\title{
Preliminary recruitment studies of the eastern oyster, Crassostrea virginica, and their potential applications, in coastal Georgia
}

\author{
Francis X. O'Beirna, Peter B. Heffernanb, Randal L. Walkera \\ aShellfish Research Laboratory, University of Georgia Marine Extension Service, 20 Ocean Science Circle, \\ Savannah, GA 31411-1011.USA \\ ๖Marine Institute, 80 Harcourt Street, Dublin 2, Ireland
}

\begin{abstract}
Oyster recruitment was monitored in Wassaw Sound, Georgia from April through October, 1991. The study was initiated to determine precise recruitment patterns of oysters over the 7 month spawning season. One of the goals was to determine the most suitable time for the collection of natural spat for maricultural, fisheries and recreational purposes. Three sites of varying hydrographic characteristics were chosen in Wassaw Sound. The sites varied in terms of temperature and salinity regimes and in their exposure to wind and wave action. Within each site, oyster recruitment was estimated at three tidal heights; subtidally, at mean low water and intertidally, approximately $2 \mathrm{~h}$ above the mean low water mark. Sampling took place so as to measure net recruitment over biweekly (BW), monthly (M) and seasonal (S) periods. The results indicated that the recruitment of oysters in this region of coastal Georgia is protracted, lasting 6 months (May through October). The levels of recruitment were very high relative to other regions on the east coast of the USA, with peak recruitment for the entire study area $(x=2800$ spat $\mathrm{m}^{-2}$ for BW and $\mathrm{X}=3020$ spat $\mathrm{m}^{-2}$ for $\mathrm{M}$ ) occurring between July and September. The intensity of recruitment varied significantly among the three sites. The most sheltered site in terms of wave exposure experienced the highest recruitment $\left(x=4380\right.$ spat m- ${ }^{2} B W ; x=6260$ spat $\left.m-^{2} M\right)$. This site also had higher overall water temperatures as well as greater daily temperature fluctuations. The least sheltered site had the lowest numbers of young oysters $(X=$ 1000 spat $\mathrm{m}^{-2}$ BW; X. $=686$ spat $\mathrm{m}^{-2} \mathrm{M}$ ), as well as having the most stable temperature regime. The biweekly samples generally experienced higher recruitment subtidally at the three sites. The monthly samples had higher numbers of oyster spat at the mean low water mark while the seasonal samples showed significantly higher recruitment intertidally (up to $x=7353$ spat m${ }^{2}$ ). The shift in recruit- ment patterns over time is partially attributed to increased subtidal predation pressure on the recruits. The collection of natural spat in relation to the natural fishery, potential maricultural activity and the recreational fishery is discussed.
\end{abstract}

Keywords: Crassostrea virginica; Recruitment studies; Culture methods 


\section{Introduction}

The eastern oyster, Crassostrea virginica, is primarily located in the intertidal zone in Georgia forming loose beds or more commonly, dominating oyster reefs (Bahr, 1976; Harris, 1980). The reefs are formed by the continuous abundant recruitment of oysters on the existing oysters. Their subsequent growth is restricted, which results in elongation of the shells (McKenzie and Badger, 1969). Such elongation greatly reduces the meat content of the oyster and their subsequent monetary value. Given the abundance of oyster larvae in the region, as attested by high recruitment exhibited (Adams et al., 1991), the potential to harvest spat for maricultural purposes is real. However, lack of knowledge previous to this study pertaining to the intensity and patterns of spatfall in the region has inhibited any such industrial diversification.

This report describes a study of the recruitment of the eastern oyster, in coastal Georgia from March through November, 1991. The study addresses a number of questions regarding larval recruitment in Georgia waters, namely: (1) What are the precise temporal variations in the recruitment patterns observed over the spawning season, which lasts for approximately 7 months (Heffernan et al., 1989)?; (2) what are the spatial variations in recruitment patterns at different sites having different hydrographic characteristics?; (3) What are the variations in recruitment at the different tidal heights? This study examines the feasibility of establishing a formal monitoring program of oyster recruitment in Georgia. From a fishery management perspective, the research was designed to determine the optimum time for: (1) the planting of cultch material on the public picking beds or, (2) the deployment of the collectors for the capture of natural spat for maricultural purposes. Both procedures would require the capture of ideal densities of oysters such that the most viable numbers of oysters are attained on collectors, while avoiding overcrowding and fouling by oysters, other organisms and sedimentary material.

\section{Methods}

Three sites (House Creek, Skidaway River and Priest Landing) were established in and around Wassaw Sound, Georgia (Fig. 1). The sites differ in hydrographic characteristics (see Table 1 for summary). Oyster recruitment was monitored at the three sites from 26 March to 22 November 1991.

\subsection{Collectors}

Recruitment was assessed using $1.9 \mathrm{~cm}$ diameter grooved P.V.C. tubing. The tubes have been used commercially for both remote and natural setting practices in the northwest USA and British Columbia, Canada (Roland and Broadley, 1990) and for research purposes, to monitor spatfall in South Carolina (Michener and Kenny, 1991). 


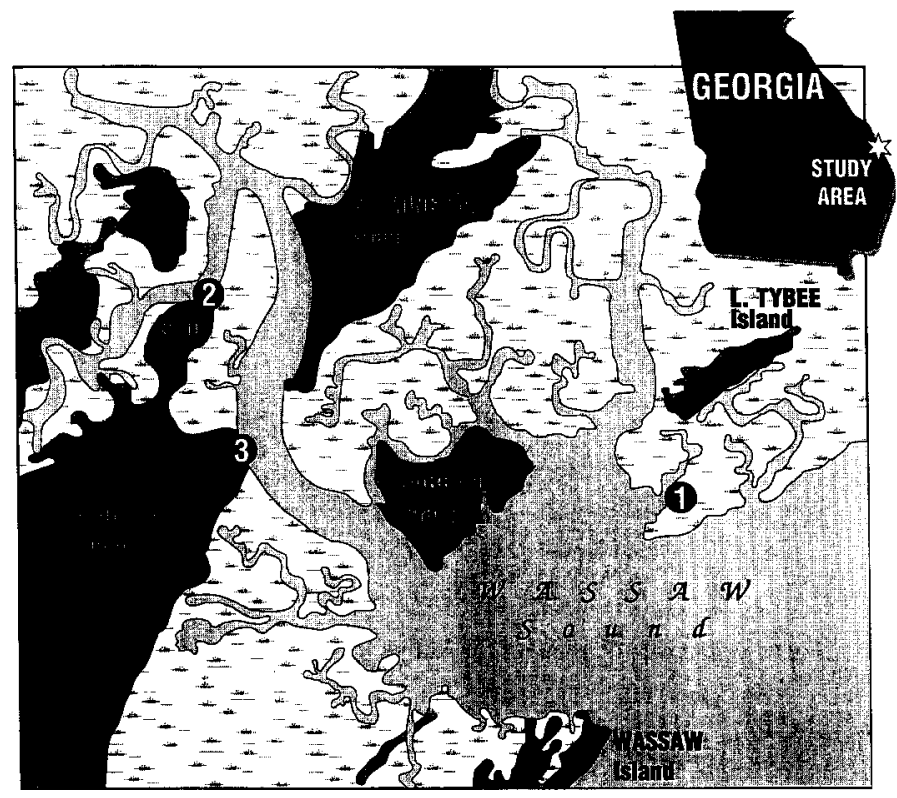

Fig. I. Site locations for the monitoring of oyster recruitment in Wassaw Sound, Georgia. I, House Creek; 2, Skidaway River near the Skidaway Institute of Oceanography (SkIO); 3, Priest Landing.

The collectors were cut in $15 \mathrm{~cm}$ segments of which only $12.5 \mathrm{~cm}$ was used in the analysis, to give a sampling area of approximately $100 \mathrm{~cm}^{2}$.

At each of the three sites, recruitment was estimated at three tidal heights: subtidally, at mean low water and intertidally approximately $2 \mathrm{~h}$ after mean low water. The three tidal heights were chosen to reflect the environmental extremes that newly set spat would be subjected to, i.e. from a zone of lower risk of desiccation and higher risk of predation to a zone of higher risk of desiccation and lower risk of predation (Castagna etal., 1988; Gibbons and Chu, 1988). The oyster collectors (grey P.V.C. tubing) were slipped over stainless steel rods in the order required by the desired tidal height and spaced apart by sections of $2 \mathrm{~cm}$ P.V.C. according to the specific tidal heights. Hereafter, each pole and its cohort of collectors is referred to as a sampling unit. The units were then suspended vertically from a frame constructed from P.V.C. $(5 \mathrm{~cm})$ at each of the sites ( Fig. 2). Upon return to the laboratory, each collector was examined under a binocular microscope and the number of oysters was counted.

Table I

Summary hydrographic characteristics of the three sites in Wassaw Sound

\begin{tabular}{lllll}
\hline Site & Temperature range & Salinity range & Degree of wave exposure & Presence of conspecifics \\
\hline House Creek & $19.5-35.5^{\circ} \mathrm{C}$ & $>25$ p.p.t. & Sheltered & Many \\
Skidaway River & $20-30^{\circ} \mathrm{C}$ & $14-28$ p.p.t. & Exposed & Moderat \\
Priest Landing & $20-30^{\circ} \mathrm{C}$ & $14-28$ p.p.t. & Exposed & e \\
\hline
\end{tabular}




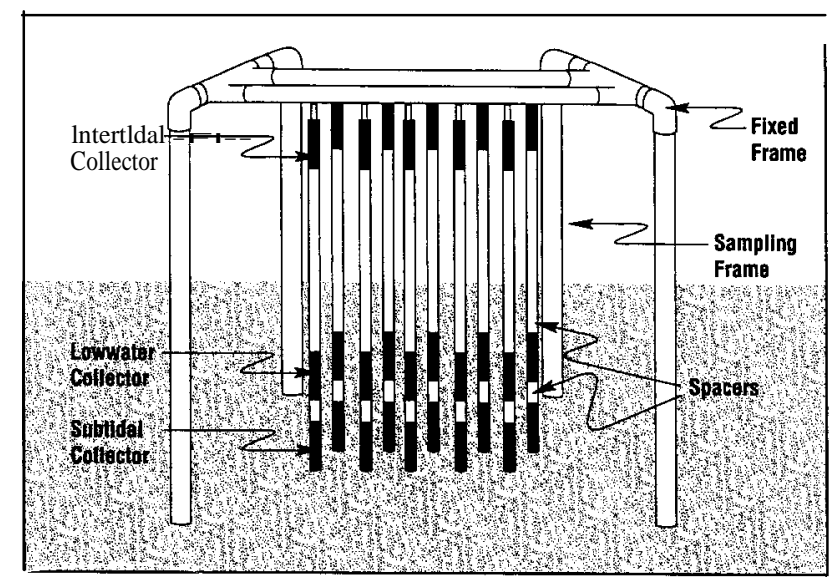

Fig. 2. Schematic diagram of the sampling appartus used in the study.

\subsection{Sampling regime}

Three sampling regimes were employed at each site. The regimes were:

(1) biweekly;

(2) monthly, both of which had five units replaced at each respective sampling dates; (3) seasonal, which comprised 15 units that were left out for the duration of the study.

\subsection{Statistical analyses}

Because the means and variances in the numbers of recruits varied substantially over time, all of the raw data for animal numbers were log transformed. Analysis of Variance (ANOVA) and Tukey Studentized Range Tests were performed on the data comparing the total numbers of oysters retrieved over the sampling period among the three sites.

\section{Results}

\subsection{Site analyses}

Oyster spat were first recorded at the House Creek site in mid-May. The levels of recruitment continued to increase gradually until the first week in July, when they peaked ( $x=43.8$ spat $0.01 \mathrm{~m}^{2}{ }^{2}$; Fig. 3a). Hereafter, all values given are in terms of spat $0.01 \mathrm{~m}-{ }^{2}$, unless otherwise stated. Young oysters continued to be recorded on collectors at this site $(x>20)$ until mid-September after which the numbers tapered off. Oyster recruitment, at the Skidaway River site, was first detected at the end of May and gradually increased to a peak $(x=32)$, in mid-August, (Fig. 3a). The numbers immediately dropped off at the next sampling but increased again in mid-September $(x=15)$. Newly settled oyster spat were not recorded at the Priest Landing site until the first week in June, (Fig. 3a). 


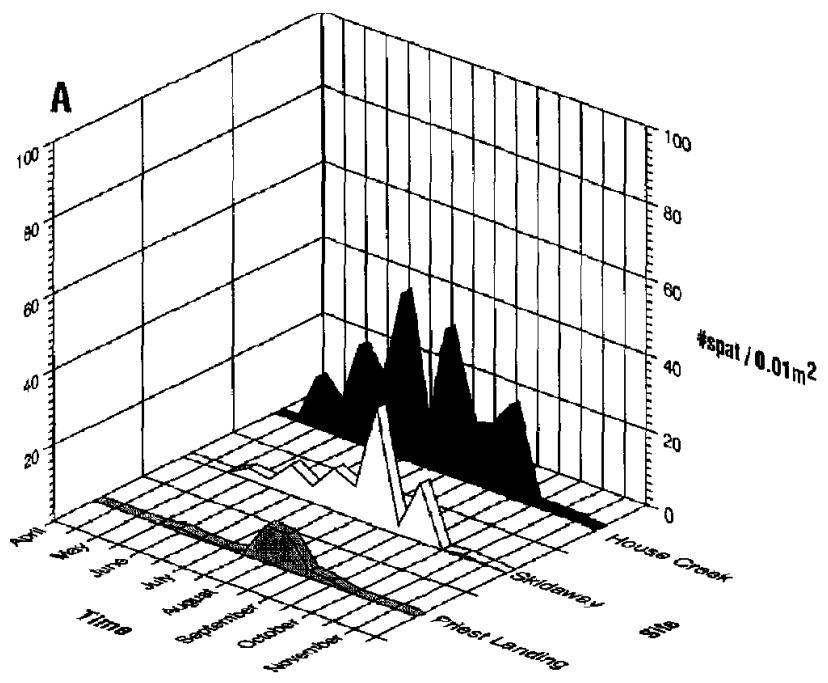

Tukey Test; House Creek > Skldaway > Priest landing, $\mathrm{P}<0.0001$

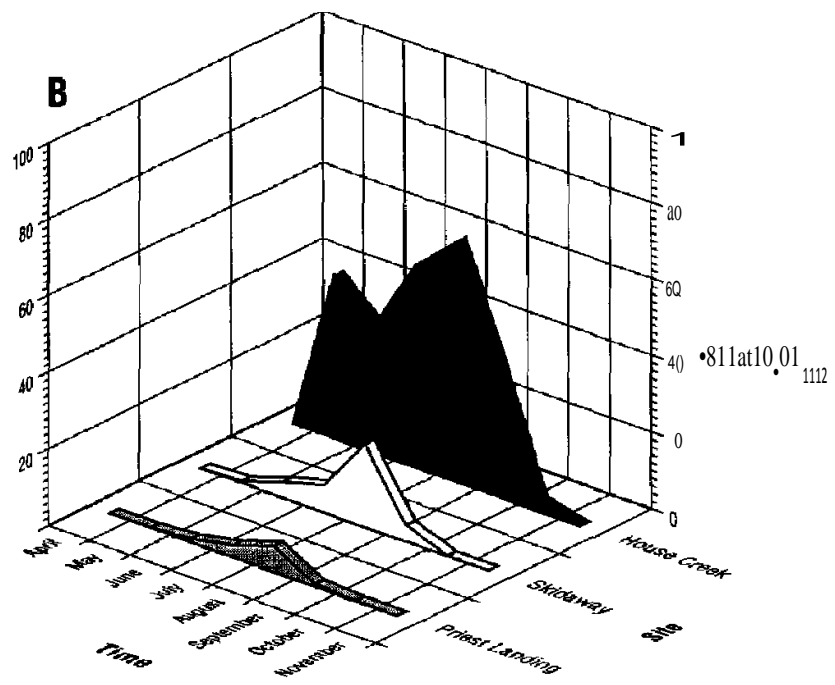

Tukey Test; House Creek $>$ Skidaway = Priest Landing, $\mathrm{p}<0.0001$

Fig. 3. Pooled data at the three sampling sites with the results of the Tukey Studentized Range test for. (A) the biweekly data and (B) the monthly data. 


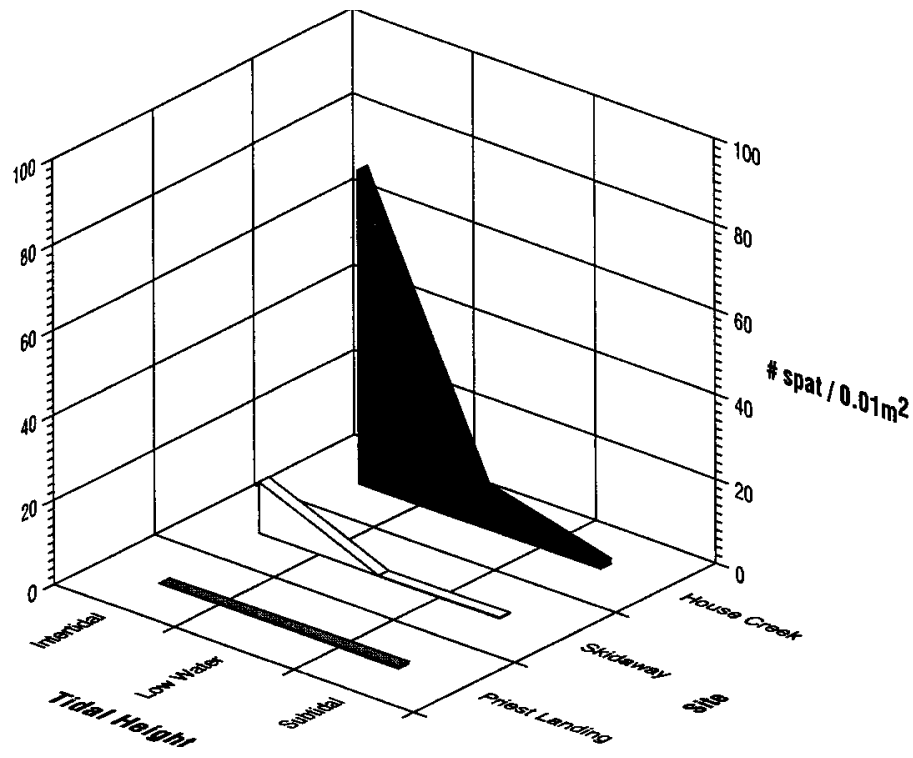

Tukey tests;

House Creek $>$ Skidaway $>$ Priest Landing, $\mathrm{P}<0.0001$

House Creek

Intertidal (IT) $>$ Low Water (LW) $>$ Subtidal $($ ST $\}, P<0.0001$

Skidaway

Intertidal $($ IT $\}>$ Low Water $($ LW) $=$ Subtidal $(\mathrm{ST}\}, \boldsymbol{P}<0.0001$

Priest Landing

Subtidal $(\mathrm{ST})=$ Low Water $(\mathrm{LW})=$ Subtidal $(\mathrm{ST}\}, \boldsymbol{P}<0.5341$

Fig. 4. Seasonal results for the three tidal heights at the three sampling sites with the results of the Tukey Studentized Range test.

The numbers of oysters captured increased to a peak in mid-July $(x=10.1)$, after which they gradually tapered off.

Given the total numbers of oysters retrieved from all the tidal heights at the three sites over all of the biweekly sampling periods; House Creek had significantly higher numbers of recruits than the Skidaway River site which in turn had significantly higher numbers of recruits than the Priest Landing site $(P<0.0001$; Fig. 3a). For the monthly data, House Creek recruitment $(X=62.6)$ was significantly higher than the recruitment data from the Skidaway River $(x=21.8)$ and Priest Landing $(x=6.8)(P<0.0001$; Fig. 3b). A similar result to the biweekly data was obtained for the seasonal data in that, House Creek $(x=$ 28) had significantly higher recruitment than Skidaway $(x=4.5)$ which had higher recruitment than Priest Landing $(x=1.1)(P<0.0001$; Fig. 4).

\subsection{Tidal height analysis}

At House Creek there was significantly higher recruitment subtidally ( $X=18.8$ ) than at the other two tidal heights (Fig. Sa) for the biweekly data. The monthly data for House 

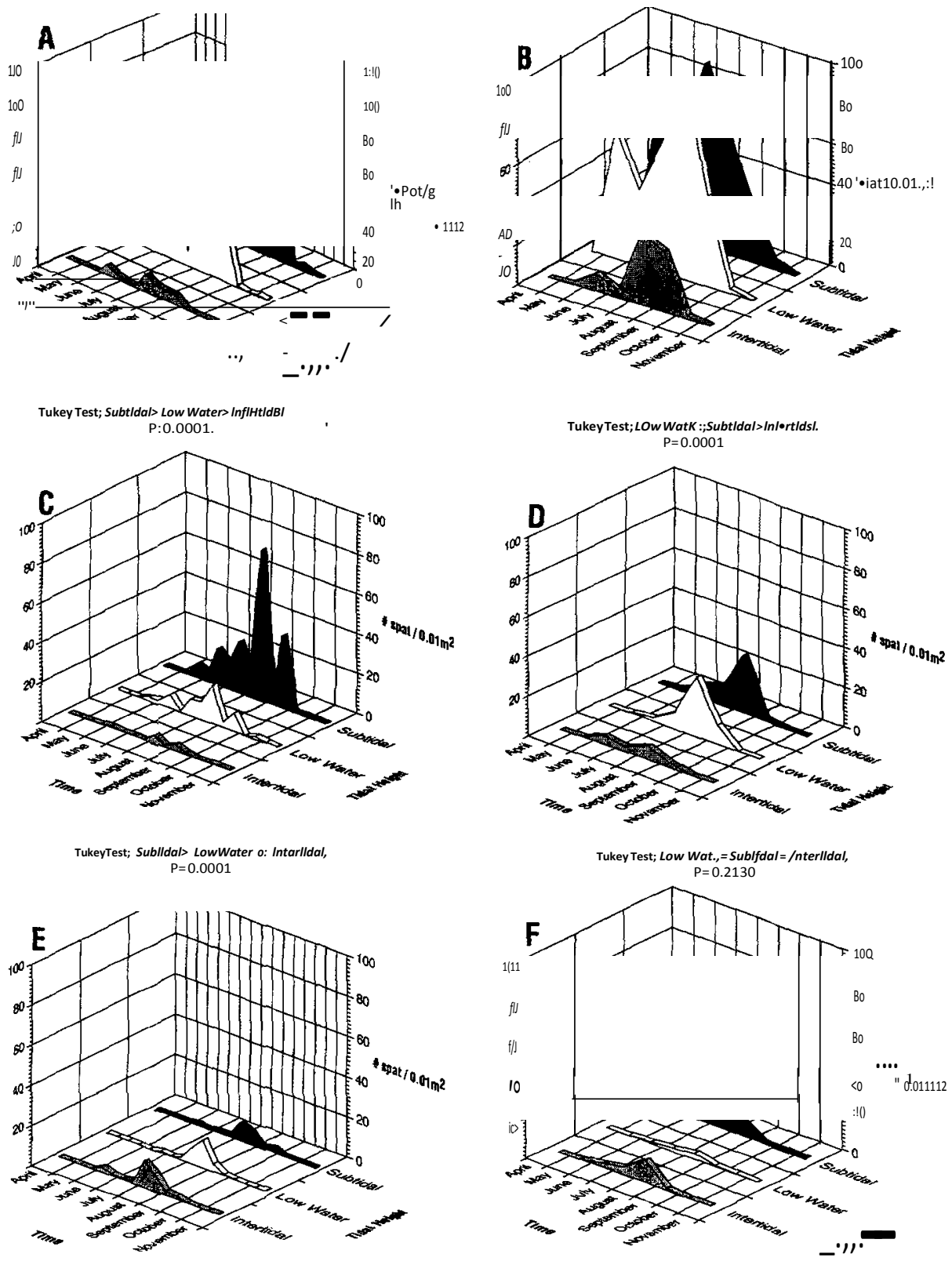

Tukey Test; Intertidal> Low Water> Subtldsl,

P: 0.5964

Tukey Test; Intertidal= SuOtIdal $=$ Lo1 $¥$ Water, P:0.1436

Fig. 5. Tidal height analysis with the Tukey Studentized Range test results for; (a) House Creek biweekly data; ( b) House Creek monthly data; (c) Skidaway River biweekly data; (d) Skidaway River monthly data; (e) Priest Landing biweekly data; (f) Priest Landing monthly data. 
Creek shows the mean low water $(x=38.7)$ and subtidal $(x=36.5)$ data were not statistically different; however, both were significantly higher than the intertidal values ( $x=9.9$; Fig. 5b). A complete shift can be observed with the seasonal data for House Creek; in that, the intertidal collectors $(X=73.5)$ had significantly higher recruitment than the mean low water collectors $(x=9.1)$ which in turn had higher recruitment than the subtidal collectors $\{x=1.3$; Fig. 4).

At the Skidaway River site, the subtidal returns $(x=12.1)$ were significantly higher than the mean low water $\{X .=3.9)$ and intertidal $(x=0.6)$ values (Fig. $5 c)$. There were no significant differences in recruitment between the tidal heights for the monthly data (Fig. 5d). The Skidaway site showed a similar recruitment shift observed at the House Creek site for the seasonal data. There was significantly higher recruitment intertidally $(x=12.2)$ than both the mean low water $(x=0.1)$ and subtidal $(x=0.3)$ levels (Fig. 4). Priest Landing had no significant differences in spatfall levels between the tidal heights for the biweekly (Fig. 5e), monthly (Fig. 5f) and seasonal (Fig. 4) data sets.

\section{Discussion}

\subsection{Recruitment patterns}

One of the primary aims of the study was to determine oyster recruitment patterns in an estuarine marsh system of coastal Georgia. At House Creek, recruitment appeared as a continuous process from May through September. At the Skidaway River and Priest Landing sites a narrower recruitment period is apparent, characterized by low levels early on, with a notable peak period from mid-July through August (Fig. 3a,b). The overall broad window of recruitment is comparable to that obtained elsewhere in the southeastern USA (Kenny et al., 1990; Michener and Kenny, 1991), and contrasts with the much narrower patterns observed in more northerly latitudes, e.g. the Chesapeake Bay (Kennedy, 1980; Haven and Fritz, 1985). The levels of oyster recruitment observed were high (300-7600 spat $\mathrm{m} \mathrm{-}^{2}$ ) when compared to levels obtained elsewhere in the southeastern USA (444-3100 spat $\mathrm{m}^{-2}$ : Kenny et al., 1990).

\subsection{Intersite comparisons}

Recruitment was significantly higher at House Creek than the other two sites. There appears to be a relationship between the level of recruitment and the degree of shelter ( albeit a qualitative parameter) from wind and wave action afforded each site. House Creek is the most sheltered of the three sites and the Skidaway River site is more sheltered than the Priest Landing site. As wave exposure increases, the levels of oyster recruitment appears to decrease. The incidence of lower oyster recruitment allied to an increase in the levels of wave exposure and higher kinetic energy at a particular site concur with the findings of Ortega (1981) and Bushek (1988). As previously stated, the duration of the recruitment season in this study is similar to that observed in Kenny et al. (1990). However, a major difference that does occur between this study and the Kenny et al. (1990) study is the degree of variability among the sites. 


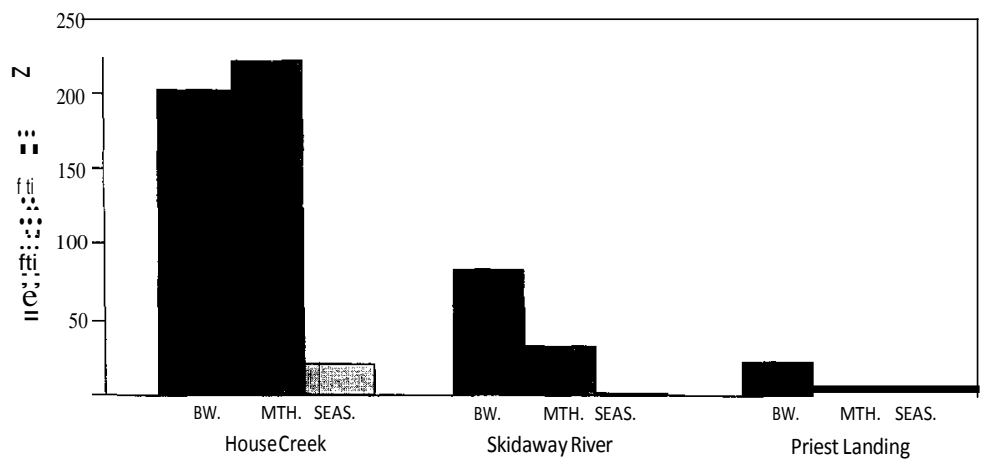

Fig. 6. Cumulative biweekly (BW) and monthly (MTH) data over the sampling period and seasonal (SEAS) data for each of the three sites.

In this study the intersite variability is high as compared with the non-significant differences obtained at North Inlet. These differences are possibly attributable to differing hydrographic characteristics at each of the Wassaw Sound sites (Table I). North Inlet had consistently high salinities throughout the Kenny et al. (1990) study (>30 p.p.t.) as well as a lower tidal amplitude. Wassaw Sound is indicative of sounds and estuaries in the southeastern USA. Consequently, these data provide a more representative picture of the degree of variability and extent of oyster recruitment for the southeastern states as a whole.

\subsection{Intrasite comparisons}

Within each of the sites, the level of recruitment for the biweekly data is as expected. The area inundated with water for longer periods, i.e. subtidal and mean low water collectors, had higher recruitment than the intertidal collectors. An exception to this however, was the Priest Landing site which did not conform to patterns observed at the other two sites. A possible reason for the non-conformity, particularly under the rigors of statistical analysis, was the low numbers of recruits recorded at this site throughout the course of the study. At House Creek and Skidaway River, initial stages of a shift in recruitment levels from subtidal to intertidal were detected upon examination of the monthly tidal height data. The subtidal returns were equal to the mean low water values for House Creek and all three tidal heights were the same for the Skidaway River site.

Cumulative biweekly and monthly values over the complete study period as well as seasonal value are displayed in Fig. 6. This exercise further highlights the effect of prolonged deployment of collectors on recruitment of oysters. The cumulative biweekly and monthly values for House Creek were somewhat similar indicating that mortality (if any) occurs within a biweekly period. The seasonal values at House Creek are substantially lower than those from the shorter sampling periods, and what might be expected if recruitment was a truly cumulative process. The other two sites had a distinct downward trend with increasing length of deployment (Fig. 6). It is appreciated that many factors could be attributed to this non-cumulative nature of oyster recruitment. 
Factors such as, predation of planktonic larvae or newly settled spat, inter/intra specific competition for resources such as food and space, non-random distribution of larvae in the water and hence, availability for settlement at a particular site and the gregarious nature of oyster settlement. Further speculation regarding the observed recruitment patterns at the different tidal heights over time is however, beyond the scope of this study.

\subsection{Applications}

The differences in recruitment observed over various temporal scales warrants serious attention when considering subsequent adult distributions and the various controlling factors have been reviewed by Michener and Kenny (1991). Increased oyster survival up the intertidal zone over longer time periods explains the existence of prominent intertidal oyster reefs and beds and the paucity of the organism subtidally on the Georgia coast. It also has serious implications when designing a program to capture natural spat. If unprotected collectors similar to those used in this study were to be used for the collection of natural spat; for what period of time must the collectors be left in the water to attain the optimum numbers of spat? Roland and Broadley (1990) recommend for P.V.C. cultch similar to that used in this study, an optimum density of 30-40 seed oysters per $1 \mathrm{~m}$ section of tubing. Greater than 50 oyster spat can be held on the tubes (Roland and Broadley, 1990). However, the risk of overcrowding is then increased. To avoid restricted growth and fusion of the shells, the oysters would then have to be separated at a younger age and the hazards associated with such a practice are high. Separation of these seed oysters would probably result in damaged shell and high mortality and the monetary returns would be reduced. In this study, the numbers of spat settling are sufficiently high throughout the summer month that the optimum density recommended by Roland and Broadley (1990) would be greatly exceeded, if collectors were left on site.

Collection of spat during peak recruitment could be a feasible venture if a protocol similar to that employed by oyster and mussel farmers in northern France was adapted (Ryther, 1968; Mason, 1991; Matthiessen, 1991); whereby, seeded cultch is moved from an area of high natural recruitment to an area oflow recruitment with medium-to-high growth potential. The primary purpose of such a practice in a Georgia context would be to reduce the level of self fouling by oysters and other organisms. Relocation of seed oysters from a high saline high recruitment area to an area of lower salinity and lower recruitment, is another alter- native. At such a site, the degree of fouling by oysters and other fouling organisms, predation pressure and disease pressure would all presumably, be reduced (Harris, 1980). Even with lower growth rates at such a site, this trade off could still be profitable given the anticipated time for growth to market size $(76 \mathrm{~mm})$ experienced in Georgia waters, i.e. less than 18 months (Heffernan and Walker, 1988). Field trials are the only means of determining the practicality of such a proposal. An alternative protocol is to confine the collection of oyster spat to the intertidal zone. The levels of spat captured in the intertidal zone over the entire season in this study ( 7000 spat $\mathrm{m} \mathrm{-}^{2}$; Fig. 6) compare favorably to other locations that require the collection of natural set to support an natural oyster fishery. For example, in France a seasonal spatfall in the region of 4,000 spat $\mathrm{m}^{-2}$ is of sufficient density to sustain a large and lucrative industry for Crassostrea gigas (Matthiessen, 1991). 
Considering the cumulative data in Fig. 6, it would seem for House Creek (or a similar tidal creek) that there would be no benefit in retrieving collectors after two weeks, since the monthly values are equivalent to the cumulative biweekly values. This would reduce the labor costs involved as well as ensure a larger spat size. For the other sites (and similar locations), it would be more beneficial to retrieve the collectors after 2 weeks if the desired goal is to collect as many spat as possible.

Lunz (1951), McNulty (1953) and Furukawa and Linton (1968), in describing recruitment patterns of oysters in the southeastern USA, all discussed the increased advantage of planting cultch late in the spawning season. Their comments were directed at the managers of commercial and recreational beds. Today, such a practice would still be practical and would optimize the numbers of spat setting on the cultch material (shell or P.V.C.), while avoiding the severe overcrowding that would be experienced in the summer months. Based on the data gathered in this study, a provisional collecting protocol would necessitate the planting of cultch material late in the spawning season, i.e. September, in and around the mean low water mark. This would reduce the exposure of newly settled spat to potential predatory organisms, while also reducing the level of overcrowding by oysters, barnacles and other epibionts (O'Beirn, unpublished data). While the growth rate will not be as high initially (approximately 3-4 $\mathrm{mm}$ per month), they would probably be high enough to justify this practice. The oysters upon reaching a sufficient size could then be bagged (to reduce the effect of macropredators) and placed subtidally off bottom to maximize growth, accord- ing to the protocol recommended by Adams et al. (1991).

In summary, oyster recruitment in the coastal waters of Georgia is of a high magnitude and prolonged nature ( 6 months), particularly when one considers the small tidal creek (House Creek) used in this study. Over short (14-28 days) sampling periods, recruitment is highest in the zones submerged for longer periods. Over longer periods of sampling ( 6 months), recruitment is much greater higher in the intertidal zone. However, the protracted recruitment season lends itself to extended collection of natural spat for maricultural pur- poses or the seeding of recreational or commercial oyster beds. The feasibility and potential for the initiation of a monitoring program of oyster recruitment is high. Also, valuable information has been gathered to optimize the collection of natural spat for maricultural purposes. Georgia and the southeast has a unique situation due to the excessively heavy and prolonged spatfall period, which requires a unique solution to develop this natural resource.

\section{Acknowledgements}

The authors would like to thank Dorset H. Hurley, Greg B. Paulk, Marie H. Bundy and the staff of the University of Georgia, Shellfish Research Lab. for their assistance throughout the course of this study. We would also like to thank sincerely Anna Boyette and Suzanne P. Mcintosh for their work on the figures and tables. The critical comments of Dr. L.R. Pomeroy, Dr. J.E. Eckman and Dr. W.K. Fitt were greatly appreciated. The authors would also like to thank Dr. J. Porter for the use of the temperature recorders. This work was funded in part by Georgia Sea Grant Project number NA84AA-D-00072. 


\section{References}

Adams, M.P., Walker, R.L., Heffernan, P.B. and Reinart, R.E., 1991. Eliminating spat settlement on oysters cultured in coastal Georgia: A feasibility study. J. Shellfish Res., 10: 207-213.

Bahr, L.M., 1976. Energetic aspects of the intertidal oyster reef community at Sapelo Island, Georgia (USA). Ecology, 57: 121-131.

Bushek, D., 1988. Settlement as a major determinant of intertidal oyster and barnacle distributions along a horizontal gradient. J. Exp. Mar. Biol. Ecol., 122: 1-18.

Castagna, M., Gibbons, M.C. and Kurkowski, K., 1988. Remote setting and post-set strategies for growing Crassostrea virginica in Virginia. J. Shellfish Res., 7:571-572.

Furukawa, A. and Linton, T.L., 1968. Oyster spat settlement patterns in a medium salinity sound of Georgia. In: T.L. Linton (Editor), Proceedings of the Oyster Culture Workshop, 11-13 July 1967, Univ. of Ga. and Ga. Game and Fish Comm., Mar. Fish. Div., Contrib. Ser. No. 6: 49-61.

Gibbons, M.C. and Chu Fu-Lin E., 1988. Does tidal zonation affect the intensity and incidence of Perkinsus marinus in juvenile American oysters in Virginia? J. Shellfish Res., 7: 572.

Harris, D.C., 1980. Survey of the intertidal and subtidal oyster resources of the Georgia coast. Georgia Dept. Nat. Resour., Coast. Resour. Div., (Project no. 2-234-R), Brunswick, GA, 44 pp.

Haven, D.S. and Fritz, L.W., 1985. Setting of the American oyster Crassostrea virginica, in the James River, Virginia, USA: temporal and spatial distribution. Mar. Biol., 86: 271-282.

Heffernan, P.B.and Walker, R.L., 1988. Preliminary observations on oyster pearl net cultivation incoastal Georgia. Northeast Gulf Sci., 10:33-43.

Heffernan, P.B., Walker, R.L. and Carr, J.L., 1989. Gametogenic cycles of three marine bivalves in Wassaw Sound, Georgia: II. Crassostrea virginica (Gmelin, 1791). J. Shellfish Res., 8: 61-70.

Kennedy, V.S., 1980. Comparison ofrecent and past patterns of oyster settlement and seasonal fouling in Broad Creek and Tred Avon River, Maryland. Proc. Natl. Shellfish. Assoc., 70: 36-46.

Kenny, P.O., Michener, W.K. and Allen, D.M., 1990. Spatial and temporal patterns of oyster settlement in a high salinity estuary. J. Shellfish Res., 9: 329-339.

Lunz, G.R., 1951. Laws for the oyster farmer. Contrib. Bears Bluff Lab. No. 10, 14 pp.

Mason, J., 1991. Production of mussels. In: C.E. Nash (Editor), Production of Aquatic Animals: Crustaceans, Molluscs, Amphibians and Reptiles. World Animal Science C, 4: 121-137.

Matthiessen, G.C., 1991. Oyster culture. In: C.E. Nash (Editor), Production of Aquatic Animals: Crustaceans, Molluscs, Amphibians and Reptiles. World Animal Science C, 4: 89-119.

McKenzie, M.D. and Badger, A.C., 1969. A systematic survey of intertidal oysters in the Savannah River basin area of South Carolina. Contrib. Bears Bluff Lab., No. 50, 15 pp.

McNulty, J.K., 1953. Seasonal and vertical patterns of oyster setting off Wadmalaw Island, S.C. Contrib. Bears Bluff Lab., No. 15, 17 pp.

Michener, W.K. and Kenny, P.O., 1991. Spatial and temporal patterns of Crassostrea virginica (Gmelin) recruitment: Relationship to scale and substratum. J. Exp. Mar. Biol. Ecol., 154:97-121.

Ortega, S., 1981. Environmental stress, competition and dominance of Crassostrea virginica near Beaufort, North Carolina, USA. Mar. Biol., 62: 47-56.

Roland, W.G. and Broadley, T.A., 1990. A manual for producing oyster seed by remote setting. Extensions Systems Branch, B.C. Ministry of Agriculture and Fisheries, Victoria, B.C., Canada, 61 pp.

Ryther, J.H., 1968. The status and potential of aquaculture, particularly invertebrate and algae culture, Part II. U.S. Dept. of Commerce, National Bureau of Standards, Washington, 261 pp. 